\title{
Herbal compound Teng-Long-Bu-Zhong-Tang inhibits metastasis in human RKO colon carcinoma
}

\author{
MENG-MENG WEI ${ }^{1-3}$, SHUANG-SHUANG WANG ${ }^{1,2}$, JIA-LU ZHENG $^{1,2}$, \\ JIN-JUN CHEN ${ }^{4}$, XIA YAN ${ }^{1,2}$, HONG-MEI AN ${ }^{5}$ and BING HU ${ }^{1,2}$ \\ ${ }^{1}$ Department of Oncology, Longhua Hospital, Shanghai University of Traditional Chinese Medicine; ${ }^{2}$ Institute of \\ Traditional Chinese Medicine in Oncology, Shanghai Academy of Traditional Chinese Medicine, Shanghai 200032; \\ ${ }^{3}$ Beizhonghe Clinics, Qingdao, Shandong 266000; ${ }^{4}$ Department of Plastic and Reconstructive Surgery, Shanghai Key Laboratory of \\ Tissue Engineering, The Ninth People's Hospital, School of Medicine, Shanghai Jiaotong University, \\ Shanghai 200011; ${ }^{5}$ Department of Science and Technology, Longhua Hospital, Shanghai University of \\ Traditional Chinese Medicine, Shanghai 200032, P.R. China
}

Received August 30, 2016; Accepted September 7, 2017

DOI: $10.3892 / o l .2017 .7206$

\begin{abstract}
Metastasis is one of the primary obstacles to the successful treatment of colorectal cancer. Teng-Long-BuZhong-Tang (TLBZT) is a modern Chinese herbal formula that may be useful in the treatment of metastatic colorectal cancer. The present study evaluated the effects of TLBZT on lung metastasis in human RKO colon carcinoma cells injected into mice via the tail vein. The results demonstrated that TLBZT inhibited the metastasis of human RKO colon carcinoma cells to the lungs. TLBZT downregulated the expression of LOX and hypoxia-inducible factor $1 \alpha$. TLBZT also inhibited the expression of integrins $\alpha \mathrm{V}$ and $\beta 3$ and the phosphorylation of focal adhesion kinase. These results indicate that TLBZT inhibits the lung metastasis of RKO colon carcinoma by regulating the expression of multiple genes. The results of the present study provide a new basis for the management of colorectal cancer metastasis using treatments derived from Chinese herbs.
\end{abstract}

\section{Introduction}

Colorectal carcinoma is the third most common cancer in males and the second most common in females (1). Metastasis is the

Correspondence to: $\mathrm{Dr}$ Bing $\mathrm{Hu}$, Department of Oncology, Longhua Hospital, Shanghai University of Traditional Chinese Medicine, 725 South Wanping Road, Shanghai 200032, P.R. China E-mail: beearhu@hotmail.com

Abbreviations: TLBZT, Teng-Long-Bu-Zhong-Tang; TCM, traditional Chinese medicine; LOX, lysyl oxidase; HIF-1 $\alpha$, hypoxia-inducible factor $1 \alpha$; DMEM, Dulbecco's modified Eagle's medium; FAK, focal adhesion kinase; ECM, extracellular matrix

Key words: colorectal carcinoma, metastasis, lysyl oxidase, hypoxia-inducible factor $1 \alpha$, integrins $\alpha \mathrm{V}$ and $\beta 3$, focal adhesion kinase primary cause of treatment failure in patients with colorectal cancer and usually occurs in the liver, lungs and other organs due to the malignant characteristics of the disease $(2,3)$. Current treatments of metastatic colorectal cancer include surgery, chemotherapy and targeted therapy, which uses small molecule-based drugs or monoclonal antibodies against abnormally expressed proteins that are essential for cancer cell growth, including anti-EGFR agents, e.g., cetuximab and panitumumab, in addition to anti-VEGF agents, e.g., bevacizumab and aflibercept (4). Due to unresectable metastatic lesions, only a small proportion of patients with metastatic colorectal cancer are eligible to undergo surgery $(5,6)$. Furthermore, chemotherapy induces toxic side effects and targeted therapy is very expensive, meaning that few patients with metastatic colorectal cancer receive suitable treatment. Currently, the 5 -year survival rate of patients with metastatic colorectal cancer is $<15 \%(7,8)$. Therefore, it is necessary to develop a novel approach to treat and prevent metastasis in colorectal cancer.

Traditional Chinese medicine (TCM) may be used as a method of treating colorectal cancer. Syndrome differentiation-based treatment with TCM decoctions can alleviate symptoms, improve quality of life and immune function, produce synergistic effects alongside anti-cancer chemotherapy, prevent cancer recurrence and metastasis and prolong the survival time of patients with colorectal cancer $(9,10)$. Based on the principles and practice of TCM, the formula, Teng-Long-Bu-Zhong-Tang (TLBZT) has been produced that may potentially be used to treat patients with colorectal cancer. Previous studies have suggested that TLBZT inhibits proliferation and induces apoptosis and senescence in colon cancer cells (11-13).

Some of the herbs present in TLBZT have been studied. Actinidia chinensis and Duchesnea indica can inhibit cell proliferation in suspension, induce active oxygen production, activate caspase-3 and induce anoikis in colorectal cancer cells $(14,15)$. Anoikis is a form of programmed cell death elicited when cells detach from the extracellular matrix 
(ECM) and is closely associated with the survival of tumor cells in a liquid environment, including the blood and lymph circulation. Therefore, inhibiting the growth of tumor cells in suspension and inducing anoikis may suppress cancer metastasis. Furthermore, Solanum nigrum, one of the herbs present in TLBZT, inhibits the proliferation, adhesion, migration and invasion of colorectal cancer cells (16). These observations suggest that TLBZT may inhibit the metastasis of colorectal cancer cells.

The present study evaluated the effect of TLBZT on colorectal cancer metastasis in vivo. The effects of TLBZT on the expression of the metastasis-associated genes, including lysyl oxidase (LOX), hypoxia-inducible factor $1 \alpha$ (HIF-1 $\alpha$ ), integrins $\alpha \mathrm{v}$ and $\beta 3$ and the phosphorylation of focal adhesion kinase (p-FAK), were also determined. The results demonstrated that TLBZT inhibits the metastasis of human RKO colon carcinoma cells to the lungs, downregulates the expression of LOX, HIF- $1 \alpha$, integrin $\alpha \mathrm{V}$ and $\beta 3$, and inhibits FAK phosphorylation.

\section{Materials and methods}

Reagents. Dulbecco's Modified Eagle's medium (DMEM) and fetal bovine serum were obtained from Hyclone; GE Healthcare Life Sciences (Logan, UT, USA). The antibody against LOX was purchased from Novus Biologicals (Littleton, CO, USA) (cat. no. NB100-2527). The antibody against HIF-1 $\alpha$ was purchased from Santa Cruz Biotechnology, Inc. (Dallas, TX, USA) (cat. no. sc-53546). Antibodies against integrins $\alpha \mathrm{V}$ (cat. no. BS3513) and $\beta 3$ (cat. no. BS1187), phosphorylated (p)-FAK (cat. no. BS4617), horseradish peroxidase (HRP)-conjugated-anti-rabbit IgG (cat. no. BS13278) and anti-Mouse IgG-HRP (cat. no. BS12478) were procured from Bioworld Technology, Inc. (St. Louis Park, MN, USA).

TLBZT extraction. The major herbs in the TLBZT formula (Chinese patent ZL200910197565.2) are: The roots of A. chinensis (30 g), S. nigrum (15 g), D. indica (15 g), Atractylodes macrocephala (9 g), Coix seed (30 g) and Viscum coloratum (15 g). All the aforementioned herbs were obtained from Longhua Hospital (Shanghai, China) in accordance with the amounts required for the TLBZT formula and decocted twice with 8 -fold distilled water at $100^{\circ} \mathrm{C}$ for $1 \mathrm{~h}$. The decoctions were merged, filtered and made up to a concentration of $1.5 \mathrm{~g}$ crude herb materials $/ \mathrm{ml}$ water and stored at $4^{\circ} \mathrm{C}$.

RKO cell culture. Human colon carcinoma RKO cells were obtained from the Cell Bank of Type Culture Collection of Chinese Academy of Sciences (Beijing, China). RKO cells were cultured in DMEM with $10 \%$ fetal bovine serum, penicillin $(100 \mathrm{U} / \mathrm{ml})$ and streptomycin $(100 \mu \mathrm{g} / \mathrm{ml})$ and maintained at $37^{\circ} \mathrm{C}$ with $5 \% \mathrm{CO}_{2}$ in a humidified atmosphere for 2-3 days until cells reached $80 \%$ confluence. Cells were subsequently passaged to new plates.

Animal model. A total of 30 male 6-7-week old BALB/c nude mice were purchased from the Shanghai SLAC Laboratory Animal Co., Ltd. (Shanghai, China). Mice were acclimatized for 1 week in pathogen-free conditions at the animal laboratory of Longhua Hospital with a $12 \mathrm{~h}$ light/dark cycle, regulated temperature of $24 \pm 2^{\circ} \mathrm{C}$ and humidity of $50 \pm 10 \%$, with ad libitum access to water and animal chow.

Mice were injected with $2 \times 10^{6} \mathrm{RKO}$ cells in $0.1 \mathrm{ml}$ PBS through the tail vein. Subsequently, mice were randomly divided into 3 groups ( $\mathrm{n}=10 \mathrm{mice} / \mathrm{group})$, and intragastrically administrated with either $11.25 \mathrm{~g} / \mathrm{kg} / 0.3 \mathrm{ml}$ TLBZT, $22.5 \mathrm{~g} / \mathrm{kg} / 0.3 \mathrm{ml}$ TLBZT or same volume of distilled water, once a day. Following 2 months treatment, mice were sacrificed by cervical dislocation, mouse lungs were removed and weighed, and metastatic nodules on the lung surface were counted. The Longhua Hospital Animal Care and Use Committee approved all studies involving mice.

Histochemistry. Lung tissues were fixed in $4 \%$ paraformaldehyde in PBS at $4^{\circ} \mathrm{C}$ overnight, embedded in paraffin and cut into $4 \mu \mathrm{m}$ thick sections. Sections were then deparaffinized with xylene two times for $10 \mathrm{~min}$, re-hydrated with 100, 95 and $70 \%$ alcohol for $2 \mathrm{~min}$, and stained with hematoxylin and eosin for $4 \mathrm{~min}$ and $1 \mathrm{~min}$ respectively, and mounted with xylene based mounting medium. Slides were visualized using an Olympus light microscope (Olympus Corporation, Tokyo, Japan).

Immunohistochemistry (IHC). Lung tissues were fixed, embedded and cut as described above. For IHC, sections were blocked with $3 \%$ hydrogen peroxide for $15 \mathrm{~min}$ at room temperature, blocked with 5\% normal goat serum (Cell Signaling Technology, Inc., Danvers, MA, USA) for $30 \mathrm{~min}$ at $37^{\circ} \mathrm{C}$, and subsequently incubated with primary antibodies against LOX (1:100), integrin $\alpha \mathrm{V}(1: 100)$, integrin $\beta 3$ (1:100), p-FAK $(1: 100)$ and HIF-1 $\alpha(1: 200)$ at $4{ }^{\circ} \mathrm{C}$ overnight. Sections were then incubated with the appropriate HRP-conjugated anti-rabbit/anti mouse $\operatorname{IgG}$ secondary antibody $(1: 4,000)$ at $37^{\circ} \mathrm{C}$ for $30 \mathrm{~min}$ and visualized using 3,3-diaminobenzidine at room temperature for 3-5 min. Sections were then counterstained with hematoxylin for $45 \mathrm{sec}$ at room temperature and mounted with glass coverslips. Slides were observed using an Olympus light microscope (Olympus Corporation). Five fields at x200 magnification were randomly selected from each slide and analyzed using Image-Pro Plus 6.0 software (Media Cybernetics, Rockville, MD, USA).

Statistical analyses. Data are expressed as the mean \pm standard deviation. Differences among groups were analyzed using one-way analysis of variance followed by a least significant difference (LSD) test. $\mathrm{P} \leq 0.05$ was considered to indicate a statistically significant difference.

\section{Results}

TLBZT inhibits the lung metastasis of colorectal cancer cells. Following treatment with TLBZT, lungs from nude mice were removed and weighed, and the number of metastatic nodules on the lung surface was counted. The results demonstrated that the number of metastatic nodules on the lung surface decreased following treatment with TLBZT in a dose-dependent manner (Fig. 1A; P<0.05). Furthermore, lung weight was significantly reduced in a dose-dependent manner following treatment with TLBZT (Fig. 1B; P<0.05). Pathology indicates that TLBZT markedly inhibited the growth of metastatic nodules in the 


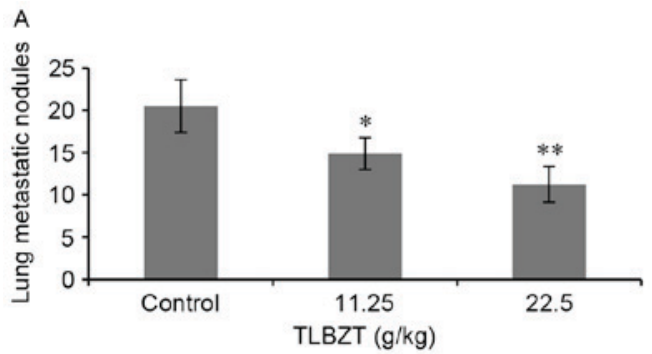

C

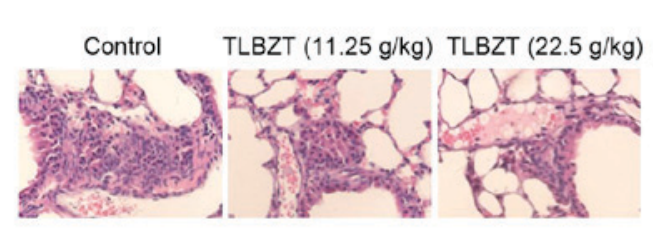

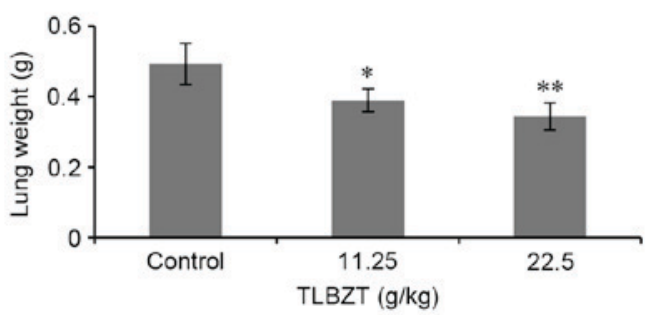

D

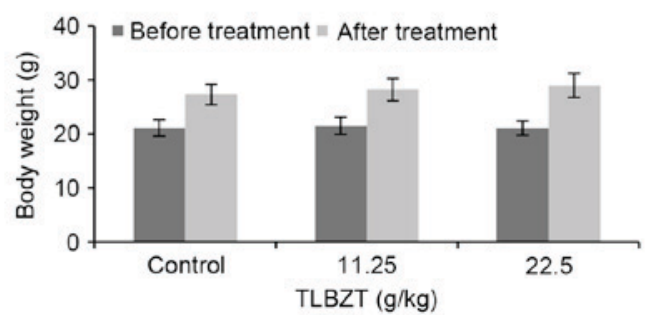

Figure 1. Effect of TLBZT on the metastasis of colorectal cancer to the lungs. Male BALB/c nude mice were injected $2 \times 10^{6}$ RKO cells through the tail vein and received intragastric administration of $11.25 \mathrm{~g} / \mathrm{kg} / 0.3 \mathrm{ml}$ or $22.5 \mathrm{~g} / \mathrm{kg} / 0.3 \mathrm{ml}$ TLBZT, or the same volume of distilled water once a day. Following 2 months treatment, mouse lungs were removed. (A) The number of metastatic nodules on the lung surface were counted. (B) Lung weights were measured (C) Hematoxylin and eosin staining indicating metastasis in the lung at x200 magnification. (D) The body weights of the mice in each group were compared prior to and following treatment. ${ }^{*} \mathrm{P}<0.05$ and ${ }^{* *} \mathrm{P}<0.01$ vs. control group. TLBZT, Teng-Long-Bu-Zhong-Tang.

A

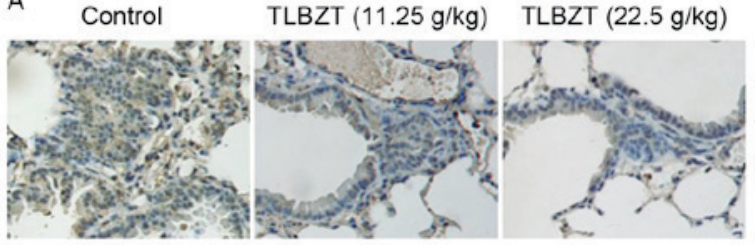

B

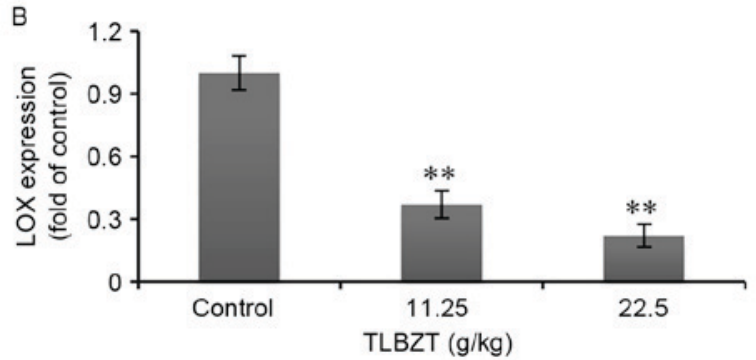

Figure 2. The effect of TLBZT on LOX expression. (A) The expression of LOX in lung metastatic lesions was detected by immunohistochemistry and observed using a microscope at $\times 200$ magnification. (B) The mean optical density of LOX was determined using Image-Pro Plus 6.0 software and expressed as a fold of the control ${ }^{* *} \mathrm{P}<0.01$ vs. control. TLBZT, Teng-Long-Bu-Zhong-Tang; LOX, lysyl oxidase.

lung (Fig. 1C). Following treatment with TLBZT, no significant adverse consequences were observed, including weight loss (Fig. 1D), ruffling of fur, changes in behavior and feeding (data not shown). These results suggest that TLBZT inhibits the metastasis of colorectal carcinoma without inducing toxicity.

TLBZT inhibits the expression of LOX. LOX is associated with the remodeling of the ECM, which serves an important role in tumor metastasis and may be a target for regulating cancer metastasis $(17,18)$. The present study demonstrated that LOX was overexpressed in lung metastases from RKO colorectal cancer and that treatment with TLBZT significantly inhibited its expression (Fig. 2; $\mathrm{P}<0.01$ ).
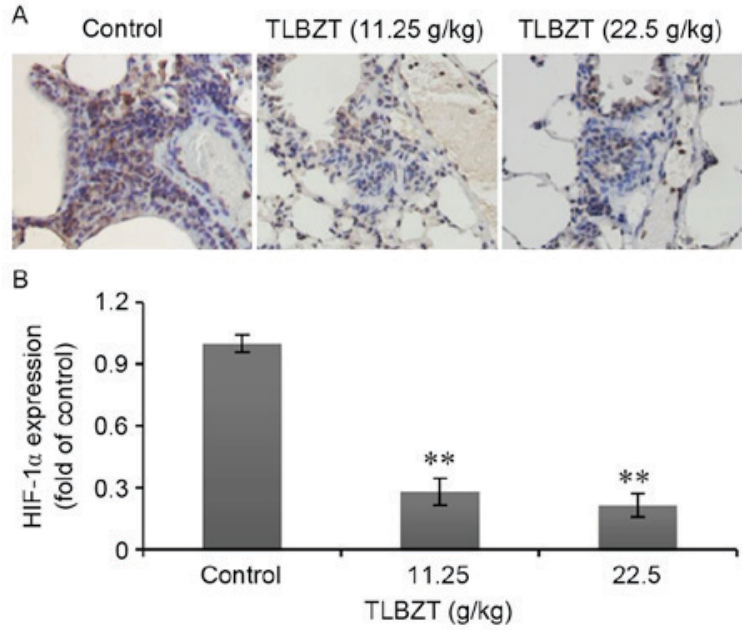

Figure 3. Effects of TLBZT on HIF-1 $\alpha$ expression. (A) The expression of HIF-1 $\alpha$ in lung metastatic lesions was detected by immunohistochemistry and observed using a microscope at x200 magnification. (B) The mean optical density of HIF-1 $\alpha$ was determined using Image-Pro Plus 6.0 software and expressed as a fold of the control ${ }^{* *} \mathrm{P}<0.01$ vs. control. TLBZT, Teng-Long-Bu-Zhong-Tang; HIF-1 $\alpha$, hypoxia-inducible factor $1 \alpha$.

TLBZT inhibits the expression of HIF-l $\alpha$. It has been demonstrated that the expression of LOX is regulated by HIF-1 $\alpha$ (19); therefore, the current study determined the effect of TLBZT treatment on HIF-1 $\alpha$ expression. The results demonstrated that HIF-1 $\alpha$ was highly expressed in lung metastases from RKO colorectal carcinoma, but that TLBZT significantly inhibited its expression (Fig. 3; $\mathrm{P}<0.01$ ).

TLBZT inhibits the expression of integrins $\alpha V$ and $\beta 3$. Integrins serve an important role in cell-cell and cell-ECM interactions and participate in the process of tumor metastasis; thus, their inhibition may suppress cancer metastasis (20-22). Therefore, the effects of TLBZT treatment on integrin expression were 

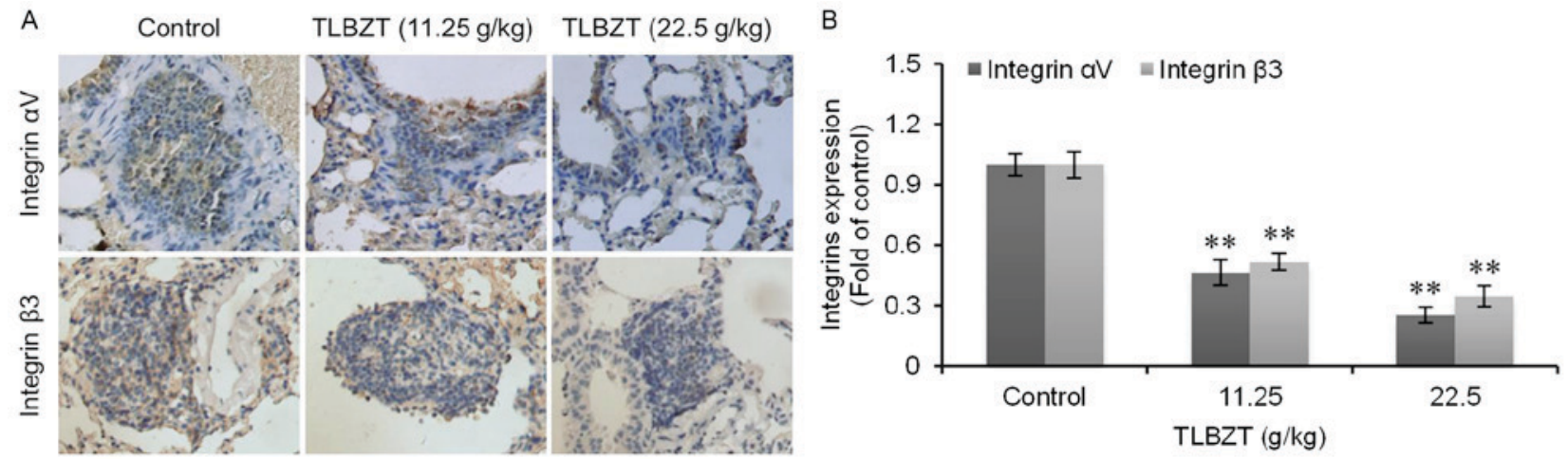

Figure 4. Effects of TLBZT on the expression of integrins. (A) The expression of integrins $\alpha \mathrm{V}$ and $\beta 3$ in lung metastatic lesions were detected by immunohistochemistry and observed using a microscope at x200 magnification. (B) The mean optical density of integrins $\alpha \mathrm{V}$ and $\beta 3$ was analyzed using Image-Pro Plus 6.0 software and expressed as a fold of the control. ${ }^{* *} \mathrm{P}<0.01$ vs. control. TLBZT, Teng-Long-Bu-Zhong-Tang.

assessed. Integrins $\alpha \mathrm{V}$ and $\beta 3$ were overexpressed in lung metastases from RKO colorectal cancer; however, treatment with TLBZT significantly inhibited their expression (Fig. 4; all $\mathrm{P}<0.01)$.

TLBZT inhibits FAK phosphorylation. The transduction of the downstream signals of integrins are associated with the phosphorylation of FAK (23), therefore the effects of TLBZT on FAK phosphorylation were assessed using immunohistochemistry. FAK was highly phosphorylated in lung metastases from RKO colorectal cancer. However, treatment with TLBZT significantly inhibited the phosphorylation of FAK (Fig. 5; $\mathrm{P}<0.01)$.

\section{Discussion}

According to TCM, the basic pathogenesis of colorectal cancer is associated with toxicity, dampness and spleen-deficiency, and the therapeutic principles of TLBZT are considered to be detoxification, overcoming dampness and tonifying the spleen $(9,10)$. Furthermore, all the herbs contained in the TLBZT formula exhibit anti-cancer effects and are commonly used in clinical oncology. A. chinensis inhibits colorectal cancer cell proliferation and induces apoptosis via mitochondrial pathways (24). S. nigrum inhibits cell proliferation, induces autophagy and enhances the cytotoxic effect of chemotherapeutic drugs in colorectal cancer cells (25). $D$. indica inhibits cell proliferation, promotes cell apoptosis and arrests the cell cycle in the S-phase in cervical cancer (26).

Atractylenolide I, a component of A. macrocephala, is able to inhibit cell survival and induce apoptosis by upregulating the expression of caspase-2, caspase- 9 and Bax, and downregulating the expression of $\mathrm{Bcl}-2$ and Bcl-XL (27). Kanglaite, a Chinese herb product extracted from the Coix seed, induces apoptosis in cancer cells and is widely used to treat different types of cancer, including lung, liver and gastric cancer (28-30). V. coloratum inhibits cell proliferation and promotes the apoptosis of colorectal cancer cells via inhibition of nuclear factor- $\mathrm{kB}$ (31). These results suggest that TLBZT is a herbal formula that exhibits anti-cancerous effects according to TCM theories and clinical practice.

LOX, a type of ECM-modifying enzyme, is involved in the remodeling of ECM. It is highly expressed in colorectal cancer
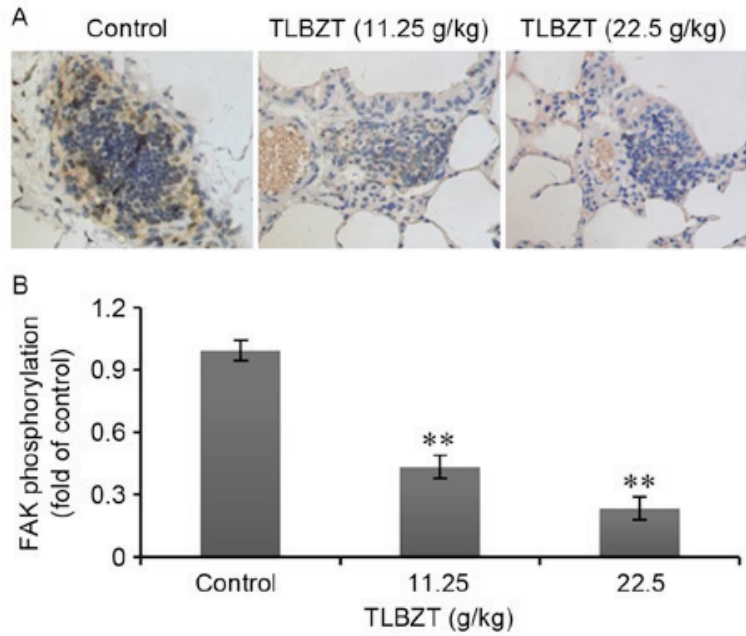

Figure 5. Effects of TLBZT on FAK phosphorylation. (A) The phosphorylation of FAK in lung metastatic lesions was detected by immunohistochemistry and observed using a microscope at x200 magnification. (B) The mean optical density of FAK phosphorylation was determined with Image-Pro Plus 6.0 software and expressed as a fold of the control. ${ }^{* *} \mathrm{P}<0.01$ vs. control. TLBZT, Teng-Long-Bu-Zhong-Tang; FAK, focal adhesion kinase.

and is considered to promote tumor metastasis $(17,18,32,33)$. Inhibiting LOX expression impairs tumor cell metastasis, therefore LOX has become a target for cancer treatment $(34,35)$. The expression of LOX is regulated by HIF- $1 \alpha$, which is degraded by ubiquitination in normoxic conditions. However, HIF-1 $\alpha$ degradation is inhibited in hypoxic conditions and it forms heterodimers with HIF-1 $\beta$, which activates the expression of downstream genes, including vascular endothelial growth factor and LOX, which are involved in angiogenesis and metastasis (36). The results of the present study demonstrated that LOX and HIF-1 $\alpha$ are overexpressed in metastatic lesions in the lung that arise from colorectal cancer cells. Treatment with TLBZT significantly inhibited LOX and HIF-1 $\alpha$ expression, suggesting that inhibition of LOX and HIF- $1 \alpha$ contributes to the TLBZT-mediated prevention of colorectal cancer metastasis.

Integrins, consisting of $\alpha$ and $\beta$ subtypes, are transmembrane proteins that mediate cell-cell and cell-ECM interactions $(37,38)$. The extracellular domains of integrins $\alpha$ and $\beta$ form a ligand binding domain for binding ligands, 
including fibrinogen, fibronectin and intercellular adhesion molecules $(37,38)$. The downstream signal transduction of integrins is associated with the FAK signaling pathway and they are able to mediate the biological behavior of cells, including cell migration, invasion and metastasis $(23,39)$. Integrin $\alpha \mathrm{V} \beta 3$ is a heterodimer formed by the non-covalent linking of the integrin $\alpha \mathrm{V}$ and $\beta 3$ subunits. It is widely expressed in tumor tissues and is closely associated with tumor metastasis $(39,40)$. Antagonizing integrin $\alpha \mathrm{V} \beta 3$ or inhibiting its ligand, osteopontin may effectively inhibit colorectal cancer metastasis $(22,41)$. The results of the present study indicate that integrin $\alpha \mathrm{V} \beta 3$ is overexpressed and that FAK is highly phosphorylated in metastatic cells of RKO colorectal carcinoma. TLBZT may inhibit the expression of integrin $\alpha \mathrm{V} \beta 3$ and the phosphorylation of FAK. These results suggest that inhibiting integrin $\alpha \mathrm{V} \beta 3$-FAK signal transduction may induce the anti-metastatic effects observed following treatment with TLBZT in colorectal cancer.

To conclude, the present study demonstrated that TLBZT inhibits the metastasis of RKO colorectal cancer cells and that this may be associated with the inhibition of HIF1 $\alpha$-LOX and integrin $\alpha \mathrm{V} \beta 3$-FAK signal transduction. These results provide a novel insight for the treatment and prevention of colorectal cancer metastasis with TLBZT.

\section{Acknowledgements}

The present study was supported by National Natural Science Foundation of China (grant nos. 81273726 and 81473625), the Program from Science and Technology Commission of Shanghai Municipality (grant no. 16401902500), the Three-year Action Program of Shanghai Municipality for Traditional Chinese Medicine (grant no. ZY3-CCCX-3-3025) and the Opening Research Fund of Shanghai Key Laboratory of Tissue Engineering (grant no. TE1401).

\section{References}

1. Torre LA, Bray F, Siegel RL, Ferlay J, Lortet-Tieulent J and Jemal A: Global cancer statistics, 2012. CA Cancer J Clin 65: 87-108, 2015.

2. Bognár G, Ledniczky G, István G and Ondrejka P: Molecular mechanisms in development of colorectal cancer metastasis. Magy Seb 59: 342-349, 2006 (In Hungarian).

3. Geiger TR and Peeper DS: Metastasis mechanisms. Biochim Biophys Acta 1796: 293-308, 2009.

4. Ohhara Y, Fukuda N, Takeuchi S, Honma R, Shimizu Y, Kinoshita I and Dosaka-Akita H: Role of targeted therapy in metastatic colorectal cancer. World J Gastrointest Oncol 8: 642-655, 2016.

5. Moorcraft SY, Ladas G, Bowcock A and Chau I: Management of resectable colorectal lung metastases. Clin Exp Metastasis 33: 285-296, 2016

6. Smith JJ and D'Angelica MI: Surgical management of hepatic metastases of colorectal cancer. Hematol Oncol Clin North Am 29: 61-84, 2015.

7. Davies JM and Goldberg RM: Treatment of metastatic colorectal cancer. Semin Oncol 38: 552-560, 2011.

8. Siegel RL, Miller KD and Jemal A: Cancer statistics, 2016. CA Cancer J Clin 66: 7-30, 2016.

9. Deng S, Hu B and An HM: Traditional Chinese medicinal syndromes and treatment in colorectal cancer. J Cancer Ther 3: 888-897, 2012

10. Deng S, Hu B and Shen KP: Pathogenesis and treatment of colorectal cancer in traditional Chinese medicine. World Sci Technol Mod Trad Chinese Med Mater Med 14: 1858-1862, 2012 (In Chinese).
11. Hu B, An HM, Shen KP and DU Q: Effects of Tenglong Buzhong Decoction on proliferation and apoptosis of human colon carcinoma cell line LS174T. Zhong Xi Yi Jie He Xue Bao 8: 575-580, 2010 (In Chinese).

12. Hu B, An HM, Shen KP and Du Q: Senescence-inducing effects of Chinese herbal medicine Tenglong Buzhong Decoction on human colon carcinoma LS-174-T cells and the mechanism. Zhong Xi Yi Jie He Xue Bao 8: 1048-1052, 2010 (In Chinese).

13. Deng S, Hu B, An HM, Du Q, Xu L, Shen KP, Shi XF, Wei MM and $\mathrm{Wu}$ Y: Teng-Long-Bu-Zhong-Tang, a Chinese herbal formula, enhances anticancer effects of 5-fluorouracil in CT26 colon carcinoma. BMC Complement Altern Med 13: 128, 2013.

14. Hu B, Shen KP, Shi XF, Deng S and Wei MM: Root of Actinidia chinensis induces anoikis in colon carcinoma RKO cells. Chin J Exp Tradit Med Formul 19: 242-245, 2013 (In Chinese).

15. Hu B, Shen KP, Shi XF, Deng S and Wei MM: Experimental research of RKO cell anoikis induced by Duchesnea indica in human colon cancer. World J Integr Trad West Med 8: 69-72, 2013 (In Chinese).

16. Hu B, An HM, Shen KP, Shi XF, Deng S and Wei MM: Effect of Solanum nigrum on human colon carcinoma RKO cells. Zhong Yao Cai 36: 958-961, 2013 (In Chinese).

17. Xiao Q and Ge G: Lysyl oxidase, extracellular matrix remodeling and cancer metastasis. Cancer Microenviron 5: 261-273, 2012.

18. Cox TR, Gartland A and Erler JT: Lysyl oxidase, a targetable secreted molecule involved in cancer metastasis. Cancer Res 76: 188-192, 2016.

19. Ji F, Wang Y, Qiu L, Li S, Zhu J, Liang Z, Wan Y and Di W: Hypoxia inducible factor $1 \alpha$-mediated LOX expression correlates with migration and invasion in epithelial ovarian cancer. Int J Oncol 42: 1578-1588, 2013.

20. Felding-Habermann B: Integrin adhesion receptors in tumor metastasis. Clin Exp Metastasis 20: 203-213, 2003.

21. Zhang Y, Yang M, Ji Q, Fan D, Peng H, Yang C, Xiong D and Zhou Y: Anoikis induction and metastasis suppression by a new integrin $\alpha v \beta 3$ inhibitor in human melanoma cell line M21. Invest New Drugs 29: 666-673, 2011.

22. Reinmuth N, Liu W, Ahmad SA, Fan F, Stoeltzing O, Parikh AA, Bucana CD, Gallick GE, Nickols MA, Westlin WF and Ellis LM: Alphavbeta3 integrin antagonist S247 decreases colon cancer metastasis and angiogenesis and improves survival in mice. Cancer Res 63: 2079-2087, 2003.

23. Mitra SK and Schlaepfer DD: Integrin-regulated FAK-Src signaling in normal and cancer cells. Curr Opin Cell Biol 18: 516-523, 2006.

24. Chen YJ and Shi RJ: Ethanol extract from radix of Actinidia chinensis inhibits cell proliferation and indeuces apoptosis in human colon carcinoma cell line LoVo. World Chin J Digest 20: 1657-1661, 2012 (In Chinese).

25. Tai CJ, Wang CK, Tai CJ, Lin YF, Lin CS, Jian JY, Chang YJ and Chang CC: Aqueous extract of Solanum nigrum leaves induces autophagy and enhances cytotoxicity of cisplatin, doxorubicin, docetaxel, and 5-fluorouracil in human colorectal carcinoma cells. Evid Based Complement Alternat Med 2013: 514719, 2013.

26. Peng B, Hu Q, Liu X, Wang L, Chang Q, Li J, Tang J, Wang N and Wang Y: Duchesnea phenolic fraction inhibits in vitro and in vivo growth of cervical cancer through induction of apoptosis and cell cycle arrest. Exp Biol Med (Maywood) 234: 74-83, 2009.

27. Liu H, Zhu Y, Zhang T, Zhao Z, Zhao Y, Cheng P, Li H, Gao H and Su X: Anti-tumor effects of atractylenolide I isolated from Atractylodes macrocephala in human lung carcinoma cell lines. Molecules 18: 13357-13368, 2013.

28. Liu X, Yang Q, Xi Y, Yu K, Wang W, Zhao X and Kou X: Kanglaite injection combined with chemotherapy versus chemotherapy alone in the treatment of advanced non-small cell lung carcinoma. J Cancer Res Ther 10 (Suppl 1): S46-S51, 2014.

29. Fu F, Wan Y, Mulati and Wu T: Kanglaite injection combined with hepatic arterial intervention for unresectable hepatocellular carcinoma: A meta-analysis. J Cancer Res Ther 10 (Suppl 1): S38-S41, 2014.

30. Zhan YP, Huang XE, Cao J, Lu YY, Wu XY, Liu J, Xu X, Xiang J and Ye LH: Clinical safety and efficacy of Kanglaite ${ }^{\circledR}$ (Coix seed oil) injection combined with chemotherapy in treating patients with gastric cancer. Asian Pac J Cancer Prev 13: 5319-5321, 2012.

31. Lin L, Ye M, Wang SM, Ni SM and Wu X: Mistletoe induces apoptosis by down-regulating the constitutive activation of nuclear factor-kB in HCT116 cells. Chin J Clin Pharm Ther 13: 730-734, 2008 (In Chinese).

32. Kim Y, Roh S, Park JY, Kim Y, Cho DH and Kim JC: Differential expression of the LOX family genes in human colorectal adenocarcinomas. Oncol Rep 22: 799-804, 2009. 
33. Ward ST, Weston CJ, Hepburn E, Damery S, Hejmadi RK, Morton DG, Middleton G, Ismail T and Adams DH: Evaluation of serum lysyl oxidase as a blood test for colorectal cancer. Eur J Surg Oncol 40: 731-738, 2014.

34. Cox TR and Erler JT: Lysyl oxidase in colorectal cancer. Am J Physiol Gastrointest Liver Physiol 305: G659-G666, 2013.

35. Bondareva A, Downey CM, Ayres F, Liu W, Boyd SK, Hallgrimsson B and Jirik FR: The lysyl oxidase inhibitor, betaaminopropionitrile, diminishes the metastatic colonization potential of circulating breast cancer cells. PLoS One 4: e5620, 2009.

36. Finger EC and Giaccia AJ: Hypoxia, inflammation, and the tumor microenvironment in metastatic disease. Cancer Metastasis Rev 29: 285-293, 2010.
37. Ley K, Rivera-Nieves J, Sandborn WJ and Shattil S: Integrinbased therapeutics: Biological basis, clinical use and new drugs. Nat Rev Drug Discov 15: 173-183, 2016.

38. Iwamoto DV and Calderwood DA: Regulation of integrin-mediated adhesions. Curr Opin Cell Biol 36: 41-47, 2015.

39. Ramsay AG, Marshall JF and Hart IR: Integrin trafficking and its role in cancer metastasis. Cancer Metastasis Rev 26: 567-578, 2007.

40. Hsu AR, Veeravagu A, Cai W, Hou LC, Tse V and Chen X: Integrin alpha $v$ beta 3 antagonists for anti-angiogenic cancer treatment. Recent Pat Anticancer Drug Discov 2: 143-158, 2007.

41. Wai PY, MiZ, Guo H, Sarraf-Yazdi S, Gao C, Wei J, Marroquin CE, Clary B and Kuo PC: Osteopontin silencing by small interfering RNA suppresses in vitro and in vivo CT26 murine colon adenocarcinoma metastasis. Carcinogenesis 26: 741-751, 2005. 